\title{
Electrooxidation of Urea and Creatinine on Nickel Foam-based Electrocatalysts
}

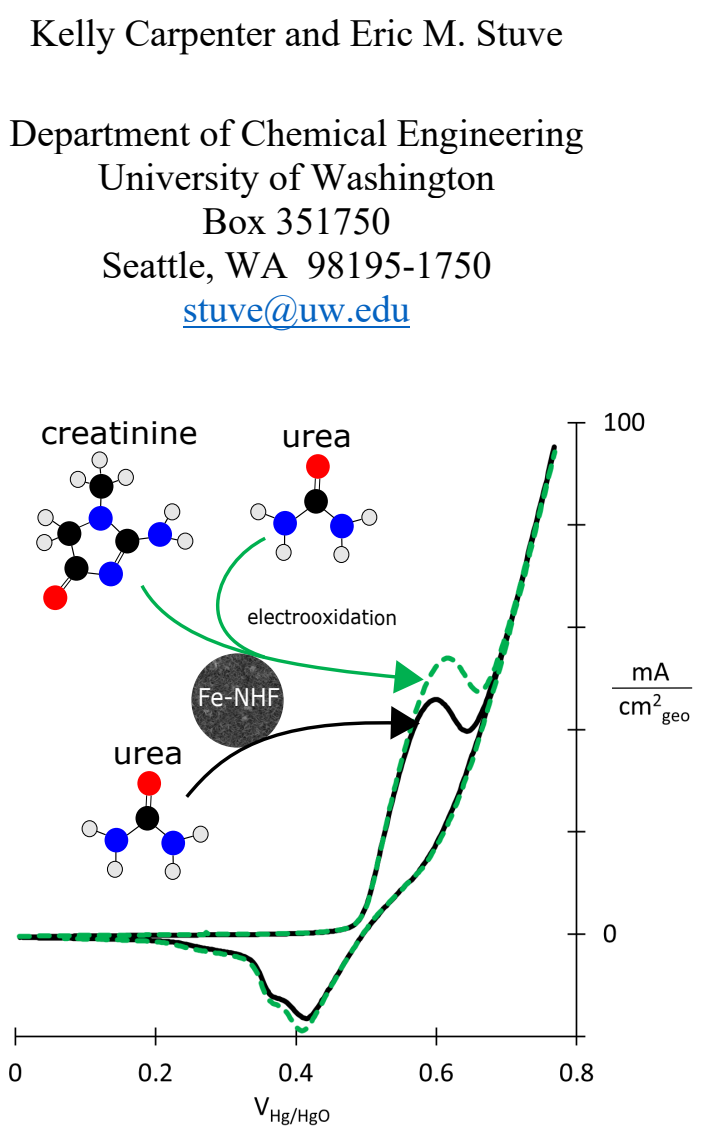

\begin{abstract}
Electrooxidation of urea and creatinine is desirable for wastewater remediation and portable dialysis to remove the two solutes from aqueous waste streams. Urine concentrations of urea $(330 \mathrm{mM})$ and creatinine $(18 \mathrm{mM})$ are relevant for wastewater remediation while portable dialysis must be able to remove blood serum concentrations of urea $(10 \mathrm{mM})$ and creatinine $(0.18 \mathrm{mM})$ from dialysate. Three nickel foam-based electrocatalysts (clean Ni foam, Ni hydroxide, and Ni hydroxide doped with $1 \mathrm{~mol} \%$ iron) were examined as substrates for the simultaneous electrooxidation of urea and creatinine. Electrodes were hydrothermally fabricated and characterized by loading, scanning electron microscopy and elemental mapping. Cyclic voltammetry and chronoamperometry were used to electrochemically evaluate the three catalysts. All electrochemical experiments were performed at room temperature and $\mathrm{pH} 14$. The results indicate that creatinine in urea solutions suppresses the oxidation current relative to urea-only solutions on Ni foam and Ni hydroxide catalysts. On iron-doped Ni hydroxide, an enhanced oxidation current occurs in cyclic voltammetry of creatinine/urea solutions, with the effect greater for dialysaterelevant concentrations. In chronoamperometry measurements, a slight decrease in oxidation current is observed for urea/creatinine solutions as compared with urea alone. This behavior is attributed to concurrent reactions of urea and creatinine subject to site blocking by adsorbed creatinine fragments that becomes evident at long time scales.
\end{abstract}

Keywords: Electrooxidation, urea, creatinine, nickel hydroxide, dialysate 


\section{Introduction}

Urea is one of the world's most abundant waste products, both industrially and biologically. Electrochemical degradation of urea from aqueous waste streams is one of the most capable removal methods for numerous technologies, mainly due to scalability [1]. Wastewater contains large quantities of urine, of which the two most abundant organic compounds are urea and creatinine. An effective method for removal of organic compounds, including both urea and creatinine, is crucial for the technologies of wastewater denitrification [2,3], portable dialysis [4,5], and potable water recovery from urine [6]. A recent electrochemical study of urine compounds [7] showed that creatinine is a significant inhibitor of the urea oxidation reaction in alkaline conditions on a $\mathrm{NiCo}_{2} \mathrm{O}_{4}$ catalyst. Apart from this 2018 study, creatinine has not been studied electrochemically, leaving it ripe for electrocatalytic research. Development of catalysts that can simultaneously oxidize urea and creatinine will be valuable to multiple industries. Furthermore, because urine and dialysate concentrations differ substantially in both scale and solute ratios, investigating each concentration regime independently is required. This study seeks to address both topics to further inform technological development in wastewater treatment.

The electrochemical oxidation of urea is well-studied due to its technological relevance [8-11]. To date, one of the best performing electrocatalysts is nickel hydroxide, $\mathrm{Ni}(\mathrm{OH})_{2}$ [12-14]. At potentials above $0.45 \mathrm{~V}$ vs. $\mathrm{Hg} / \mathrm{HgO}$ and $\mathrm{pH} 14, \mathrm{Ni}(\mathrm{OH})_{2}$ becomes electrochemically transformed into the catalytically active nickel oxyhydroxide $(\mathrm{NiOOH})$, upon which urea oxidizes to form $\mathrm{CO}_{2}, \mathrm{~N}_{2}$, and $\mathrm{H}_{2} \mathrm{O}$, regenerating the $\mathrm{Ni}(\mathrm{OH})_{2}$ surface site in the process [15]. This complete urea electrooxidation is a 6electron process. The analogous complete alkaline electrooxidation of creatinine is a 21 -electron process. Due to the high kinetic barrier for multi-electron processes, it is unlikely that creatinine completely oxidizes, though no electrochemical mechanisms have been proposed. 


\section{Experimental}

\subsection{Materials}

All chemicals were purchased from Sigma-Aldrich. The Ni and Fe salts used were ultra-high purity (99.999\% trace metal basis) while urea, creatinine, and potassium hydroxide, were ACS reagent grade.

\subsection{Hydrothermal growth and doping of nickel hydroxide}

A one-pot hydrothermal synthesis procedure $[14,16,17]$ was adapted for the growth of $\mathrm{Ni}(\mathrm{OH})_{2}$ and $1 \%$ Fe-doped $\mathrm{Ni}(\mathrm{OH})_{2}$ on $\mathrm{Ni}$ foam substrate, herein referred to as nickel hydroxy foam (NHF) and Fe-NHF, respectively. To make the NHF, $1.6 \mathrm{~mm}$ thick Ni foam was cut into three $1.0 \mathrm{~cm}^{2}$ pieces that were soaked in concentrated hydrochloric acid for 5 minutes, rinsed thoroughly with DI water, and left to dry completely in the hood before each initial mass was recorded. To make the hydrothermal solution, $0.15 \mathrm{~g}$ urea and $73 \mathrm{mg} \mathrm{Ni}\left(\mathrm{NO}_{3}\right)_{2} \cdot 6 \mathrm{H}_{2} \mathrm{O}$ were dissolved into $20 \mathrm{~mL}$ of DI water. The three clean, dry Ni foam squares were placed vertically into a $20 \mathrm{~mL}$ Teflon-lined stainless-steel hydrothermal vessel before the hydrothermal solution was poured in. With its lid secured, the vessel was placed into a $105{ }^{\circ} \mathrm{C}$ oven for 12 hours. Once removed from the oven, the vessel was allowed to cool to room temperature before it was opened. The NHF squares were removed with tweezers, rinsed with DI water and ethanol, and left to dry before their final masses were recorded.

The Fe-NHF hydrothermal solution was made using $1 \mathrm{~mol} \%$ Fe salt; the solution consisted of $0.15 \mathrm{~g}$ urea, $72 \mathrm{mg} \mathrm{Ni}\left(\mathrm{NO}_{3}\right)_{2} \cdot 6 \mathrm{H}_{2} \mathrm{O}$, and $1 \mathrm{mg} \mathrm{Fe}\left(\mathrm{NO}_{3}\right)_{3} \cdot 9 \mathrm{H}_{2} \mathrm{O}$ dissolved in $20 \mathrm{~mL}$ DI water. The growth of FeNHF was otherwise identical to that of NHF. Ni foam electrodes were also prepared for morphological and electrochemical comparison to the NHF and Fe-NHF anodes.

Each hydrothermally produced electrode was characterized based on mass loading and scanning electron microscope (FEI XL830 Dual Beam SEM/FIB) with integrated energy-dispersive spectrometer (EDS, Oxford) before being mounted onto a working electrode holder for electrochemical testing. All NHF and Fe-NHF electrodes had a total catalyst mass loading of $1 \mathrm{mg} / \mathrm{cm}^{2}$. 


\subsection{Electrochemical cell and experimental parameters}

All reported electrochemical experiments were performed in a 3-electrode cell utilizing a Ni foam, NHF, or Fe-NHF working electrode (WE), all with geometric areas of $1.0 \mathrm{~cm}^{2}$. All electrochemical data reported in a figure were obtained from the same WE, so real electrode surface area remains consistent between scans. The counter electrode (CE) was a homemade, high surface area Pt coil electrode. The reference electrode (RE) was a single junction $\mathrm{Hg} / \mathrm{HgO}$ electrode (Pine research) with $4.24 \mathrm{M} \mathrm{KOH}$ filling solution, designed for stability in alkaline conditions; all voltages reported in text and figures are in reference to $\mathrm{Hg} / \mathrm{HgO}(98 \mathrm{mV}$ vs. NHE). The background electrolyte was $1 \mathrm{M} \mathrm{KOH}$ solution with 2-330 $\mathrm{mM}$ urea and/or $0.06-18 \mathrm{mM}$ creatinine added. Urea and creatinine concentrations were chosen to mimic dilute dialysate and more concentrated urine.

The electrochemical experiments were performed using a Solartron 1287A potentiostat. All cyclic voltammograms (CVs) were performed at room temperature and a scan rate of $10 \mathrm{mV} / \mathrm{s}$ within a potential window that minimized oxygen evolution. Each CV reported is the result of the third potential cycle, though the current density did not depend on cycle number after the first cycle. The chronoamperometry (CA) voltage was chosen based on the current density maximum in the CVs. The cell was sparged with $\mathrm{N}_{2}$ during both the potentiodynamic and potentiostatic experiments to a) prohibit $\mathrm{CO}_{2}$ absorption in the alkaline electrolytes and b) dislodge gas bubbles formed during reaction on the Ni foam-based electrodes. Legends on electrochemical data figures denote concentrations for urea and creatinine using a format of Urea:Creatine (mM:mM).

\section{Results}

\subsection{Electrode characterization}

Figure 1a-c shows the SEM images of clean Ni foam, NHF, and Fe-NHF, respectively. Hydrothermal growth of $\mathrm{Ni}(\mathrm{OH})_{2}$ and $\mathrm{Fe}(\mathrm{OH})_{3}$ appear in two varieties: microparticles (Fig. 1b) and nanowalls [16] (Fig. $1 b, c)$. The hydroxy nanowalls are apparent at magnifications above $\sim 2000 \mathrm{x}$ and coat all surfaces exposed to the hydrothermal bath. When nanowalls grow on hydroxy microparticles, the structures are referred to 


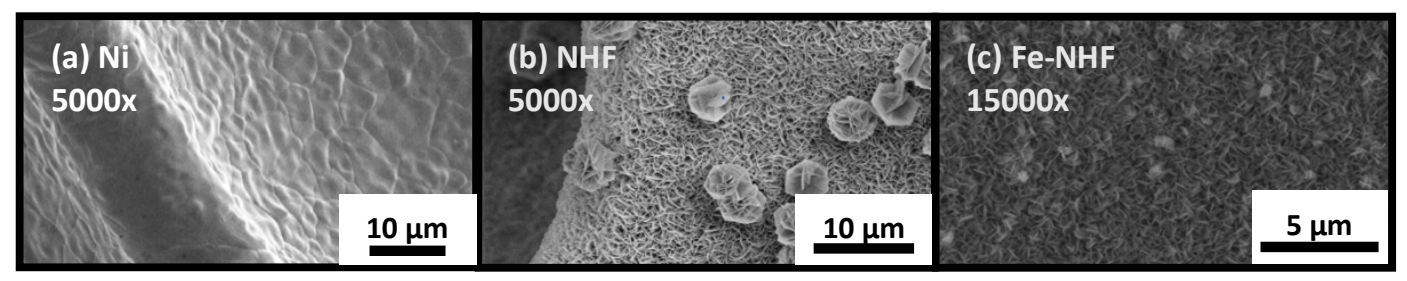

Fig. 1a-c SEM images of a) Ni foam, b) NHF, and c) Fe-NHF with magnifications noted

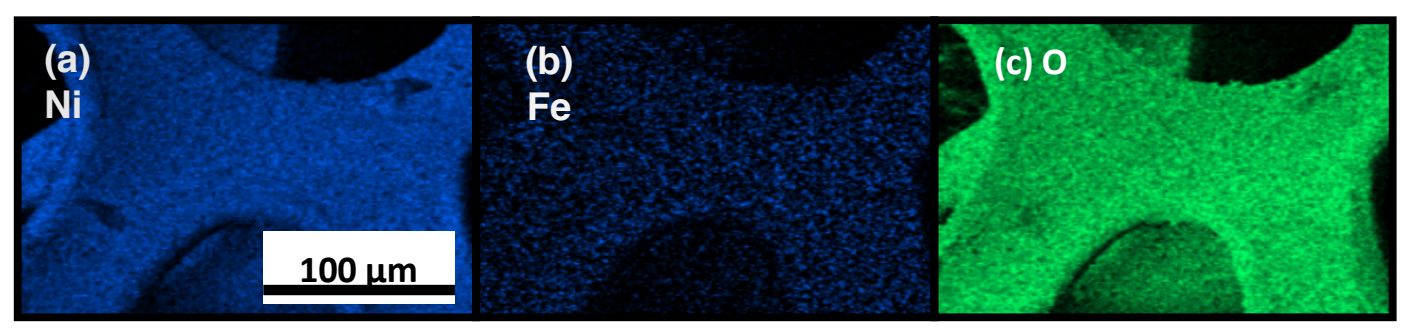

Fig. 2a-c Fe-NHF electrode EDS elemental maps for surface species of a) Ni (L series), b) Fe ( $L$ series), and c) $\mathrm{O}$ ( $\mathrm{K}$ series)

as "flowerlike" [7,18,19] (Fig. 1b). Morphologies for NHF and Fe-NHF are similar, though SEM comparison reveals fewer flowerlike structures on Fe-NHF (Fig. 1b,c). Energy-dispersive spectroscopy element maps and spectra (Fig. 2) of Fe-NHF reveal consistent distribution of Ni, Fe, and $\mathrm{O}$ throughout the sample. The EDS results indicate that Fe doping on the surface was $0.8 \%$, in reasonable agreement with the intended level of $1 \%$.

\subsection{Electrochemical experiments}

\subsubsection{Nickel foam}

The cyclic voltammograms in Figure 3 were performed on Ni foam electrodes in $1 \mathrm{M} \mathrm{KOH}$. Figure 3a is the blank $\mathrm{CV}$ without urea and shows the redox conversion of $\mathrm{Ni}(\mathrm{OH})_{2}$ to $\mathrm{NiOOH}$, occurring between potentials of $0.43 \mathrm{~V}$ and $0.55 \mathrm{~V}$. The oxidation peak shoulder is due to oxidation of $\alpha-\mathrm{Ni}(\mathrm{OH})_{2}$, while the main peak is a result of the oxidation of $\beta-\mathrm{Ni}(\mathrm{OH})_{2}$. On the return scan a double reduction peak is observed due to the reduction of $\beta-\mathrm{NiOOH}$ and $\gamma-\mathrm{NiOOH}[20]$. The oxygen evolution reaction (OER) begins at $0.62 \mathrm{~V}$ on the positive scan. The reverse scan off Fig. 3a reveals the transition of NiOOH back into $\mathrm{Ni}(\mathrm{OH})_{2}$, referred to as the $\mathrm{Ni}^{3+}$ reduction peak. The data from Fig. 3a are also included in Fig. $3 \mathrm{~b}$ for 

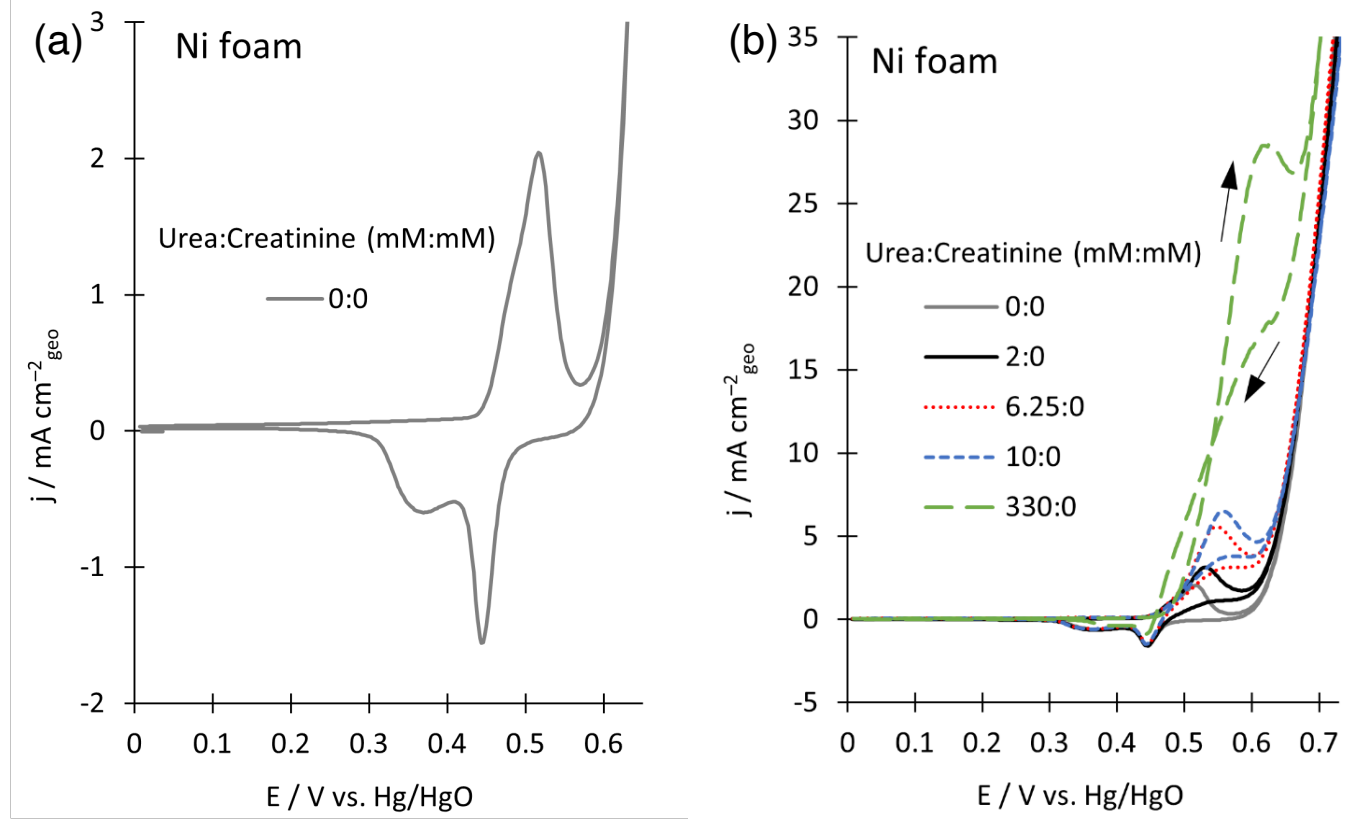

Fig. 3 Cyclic voltammograms (CV) of a) $0 \mathrm{mM}$ urea and b) 0, 2, 6.25, 10, and 330 $\mathrm{mM}$ urea on $\mathrm{Ni}$ foam in $1 \mathrm{M} \mathrm{KOH}$

reference against urea containing solutions. Urea concentrations in the range of healthy $(2 \mathrm{mM})$ to uremic $(10 \mathrm{mM})$ human serum, and $330 \mathrm{mM}$ typical of human urine, produce oxidation peaks that follow the leading edge of the $\mathrm{Ni}^{2+}$ oxidation peak. The maximum urea oxidation current density $i_{\text {max }}$ increases with urea concentration and shifts to more positive potentials, as listed in Table 1 . The return scans for the urea-containing solutions remain above the blank $\mathrm{CV}$, although without the presence of peaks. For the $330 \mathrm{mM}$ urea concentration, urea oxidation current continues into the OER region.

Two notable differences seen in the $330 \mathrm{mM}$ urea data, with respect to the lower concentration curves, are that the return scan crosses over the forward scan at about $0.54 \mathrm{~V}$, and the $\mathrm{Ni}^{3+}$ reduction peak is reduced in intensity by $63 \%$, in line with results by other researchers $[11-13,19,21]$. These two features

Table 1 Peak current densities $\left(i_{\text {mov }}\right)$ and associated potentials $\left(E_{\text {mrv }}\right)$ for each CV in Fig. 3b

\begin{tabular}{ccc}
\hline [Urea] $(\mathrm{mM})$ & $\boldsymbol{i}_{\max }\left(\mathrm{mA} / \mathrm{cm}^{2}{ }_{\text {geo }}\right)$ & $\mathrm{E}_{\max }(\mathrm{V} \mathrm{vs} \mathrm{Hg} / \mathrm{HgO})$ \\
\hline 0 & 2 & 0.52 \\
2 & 3 & 0.53 \\
6.25 & 6 & 0.55 \\
10 & 7 & 0.56 \\
330 & 28 & 0.62 \\
\hline
\end{tabular}




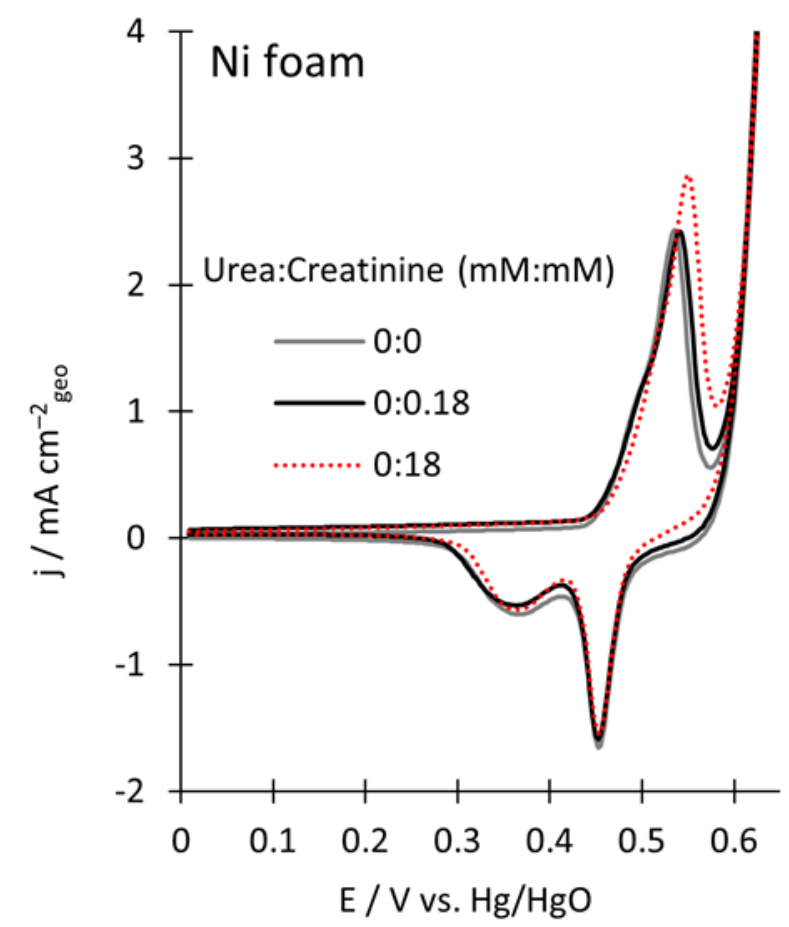

Fig. $4 \mathrm{CVs}$ of creatinine on $\mathrm{Ni}$ foam in $1 \mathrm{M} \mathrm{KOH}$ at dialysate- $(0.18 \mathrm{mM})$ and urinerelevant $(18 \mathrm{mM})$ concentrations

are not observed with dialysate-relevant solution due to the much lower urea concentration.

Figure 4 shows CVs of creatinine-only solutions with concentrations of 0.18 and $18 \mathrm{mM}$ to capture the dialysate and urine-relevant concentration regimes, respectively. The potential of the $\mathrm{Ni}^{2+}$ oxidation peak did not change with creatinine concentration, although the $18 \mathrm{mM}$ creatinine solution lacks the subtle oxidation peak at $0.48 \mathrm{~V}$ that occurs in the other two scans. The onset of OER is unchanged by creatinine. The shape of each oxidation curve resembles the blank CV, though with slightly increased current density throughout the entire positive and negative scans above $0.5 \mathrm{~V}$. Comparison of $18 \mathrm{mM}$ creatinine to the blank shows a $22 \%$ increase in oxidation charge and a $27 \%$ decrease in reduction charge, which may indicate that creatine oxidizes on $\mathrm{Ni}$, though with severe kinetic limitations compared to urea (Fig. 3b).

Figure $5 a, b$ shows that creatinine added to urea solution decreases the oxidation current on $\mathrm{Ni}$ foam in the urea oxidation region as compared to that for urea alone. To quantify differences in oxidation and reduction currents we use charge density. Oxidation charge is measured on the forward 

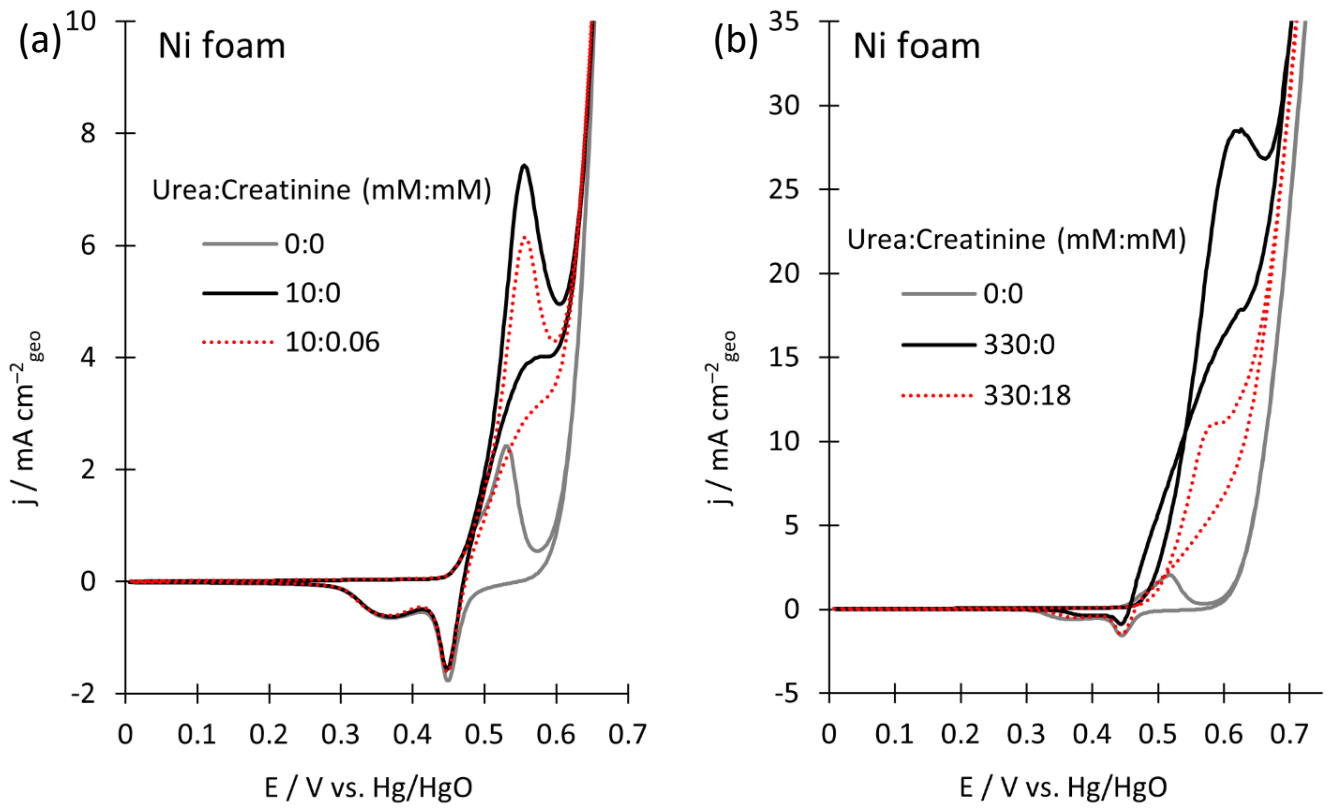

Fig. $5 \mathrm{CVs}$ of urea alone and with creatinine in $1 \mathrm{M} \mathrm{KOH}$ for a) dialysate-relevant concentrations and b) urine-relevant concentrations of each solute

scan between the voltage where current reaches $0.1 \mathrm{~mA} / \mathrm{cm}^{2}$ and the final potential. On the reverse scan oxidation charge is measured between the final potential and the potential at which the current becomes negative (reducing). The overall oxidation charge density is the addition of these two values. Reduction charge density is measured on the return scan between the potential at which the current becomes reducing and the final potential. Figure $5 a$ demonstrates a $17 \%$ decrease and Fig. $5 \mathrm{~b}$ a $52 \%$ decrease in oxidation charge, when creatinine is present (Table 2). The presence of creatinine minimally increases the oxidation voltage by $4 \mathrm{mV}$ in Fig. $5 \mathrm{a}$ and $13 \mathrm{mV}$ in Fig. $5 \mathrm{~b}$ (Table 2). The oxidation kinetics of urea are more severely limited at higher concentrations (Fig. 5b), implying that the oxidation rate of urea decreases with increasing creatinine concentration on $\mathrm{Ni}$ foam. Urea oxidation continues along with OER for all solutions (Fig. 5a, b) contributing to sustained increased current above the blank OER. In Figure $5 b$, the reduction peak for urea and creatinine is more dramatic than for the urea-only CV, in agreement with lower overall urea oxidation (Table 2) [15]. 

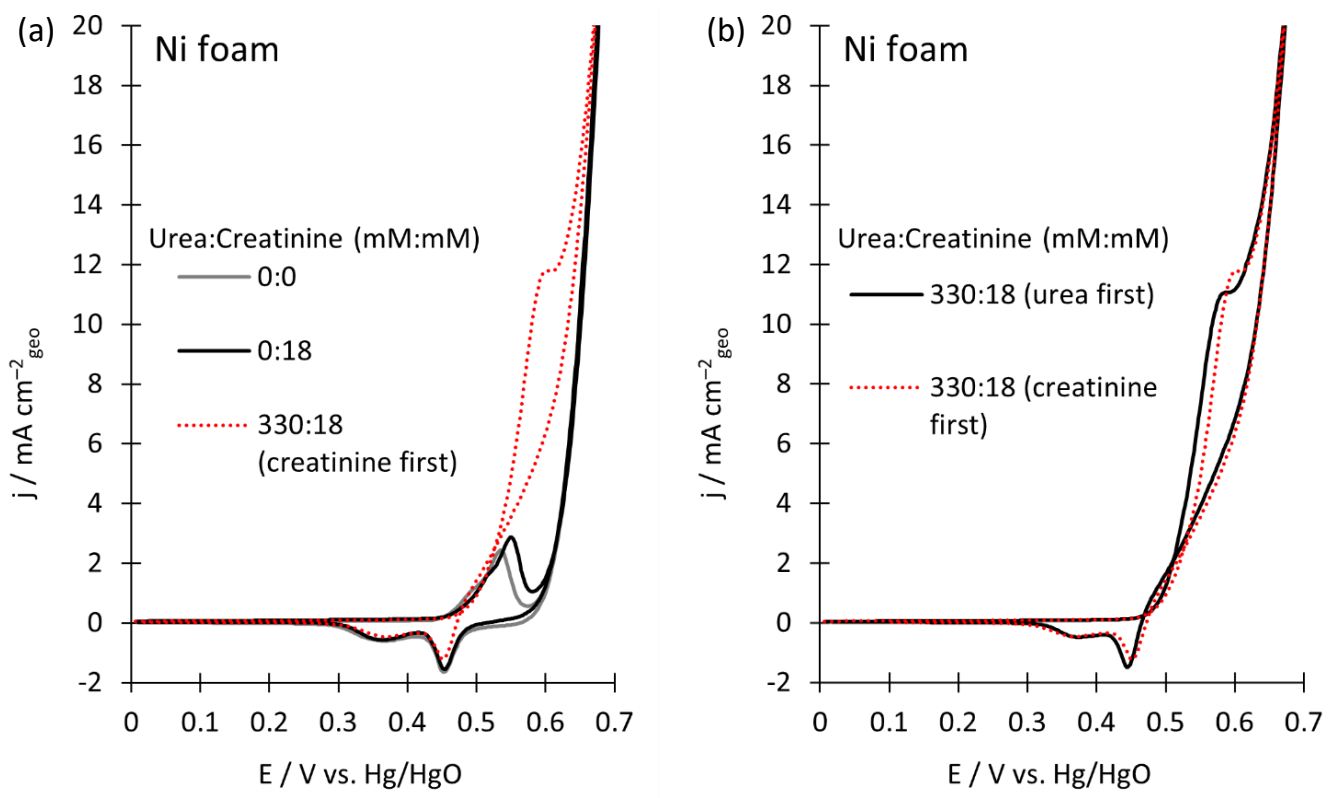

Fig. $6 \mathrm{CVs}$ of urine-relevant concentrations of creatinine and urea in $1 \mathrm{M} \mathrm{KOH}$ on $\mathrm{Ni}$ foam. a) $18 \mathrm{mM}$ creatinine added before $0.33 \mathrm{M}$ urea, b) comparison of urea and creatinine CVs from Figs. $5 \mathrm{~b}$ and $6 \mathrm{a}$

In Fig. 6a, creatinine was added prior to urea rather than vice-versa as in the experiments for Fig. 5. Figure $6 \mathrm{~b}$ demonstrates that the order of solute introduction into the cell plays a role in oxidation potential on Ni. Addition of $330 \mathrm{mM}$ urea to $18 \mathrm{mM}$ creatinine (Fig. 6a) did not match the data in Fig. 5b with the same concentrations. A $30 \mathrm{mV}$ increase in peak potential was observed when creatinine interacts with the Ni surface prior to urea, which contributes to lower overall charge passed in the urea

Table 2 Oxidation charge density, $\left(Q_{Q x}\right)$, reduction charge density $\left(Q_{\text {red }}\right)$, oxidation onset for urea-only solutions $\left(V_{v}\right)$, and oxidation onset for creatinine-containing solution $\left(V_{u+c}\right)$, extracted from the CVs in Fig. 5a,b. Oxidation onset values defined as the voltage where current density reached $0.1 \mathrm{~mA} / \mathrm{cm}^{2}$, in $\mathrm{mV}$ vs. $\mathrm{Hg} / \mathrm{HgO}$.

\begin{tabular}{ccccc}
\hline Urea:Creatinine $(\mathbf{m M}: \mathbf{m M})$ & $Q_{\text {ox }}\left(\mathbf{m C} / \mathrm{cm}^{2}\right)$ & $Q_{\text {red }}\left(\mathbf{m C} / \mathbf{c m}^{2}\right)$ & $V_{u}(\mathbf{m V})$ & $V_{u+c}(\mathbf{m V})$ \\
\hline $10: 0$ & 99.4 & -11.3 & 485 & - \\
$10: 0.06$ & 82.5 & -11.2 & - & 489 \\
$330: 0$ & 719 & -3.8 & 484 & - \\
$330: 18$ & 348 & -7.4 & - & 497 \\
\hline
\end{tabular}




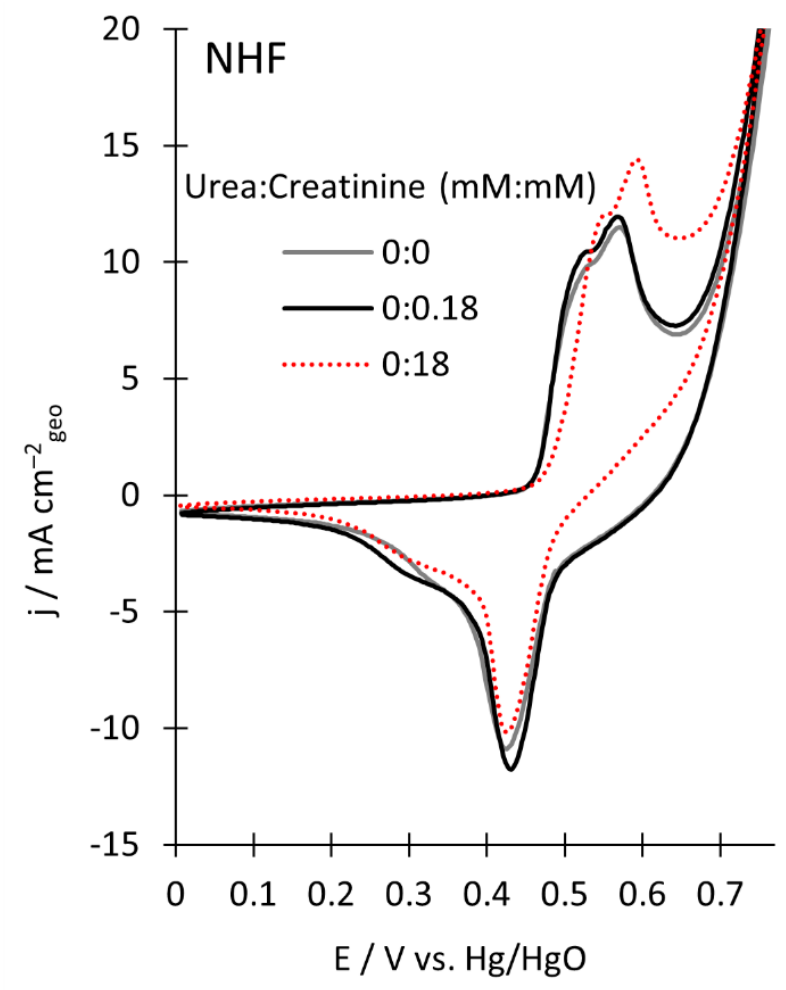

Fig. $7 \mathrm{CVs}$ of creatinine on NHF in $1 \mathrm{M} \mathrm{KOH}$ at dialysate $(0.18 \mathrm{mM})$ and urine-relevant (18 $\mathrm{mM})$ concentrations

oxidation region. It is unclear whether the difference in peak current densities of Fig. $6 \mathrm{~b}$ is attributed to minor concentration differences of between the two different solutions or differences in electrochemically active surface area between the experiments.

\subsubsection{NHF}

On a NHF electrode, the presence of $0.18 \mathrm{mM}$ creatinine had little effect on the $\mathrm{Ni}^{2+} / \mathrm{Ni}^{3+}$ transition, as shown in Fig. 7. A creatinine concentration of $18 \mathrm{mM}$ increased the peak potential by $16 \mathrm{mV}$ and contributed to a $25 \%$ charge increase, similar to that observed on Ni foam (Fig. 4). Comparison of ureaonly (black CV, Fig. 8a) and urea/creatinine solutions on NHF (colored CVs, Fig. 8a) shows that urea oxidation charge is suppressed by $3-15 \%$ in the presence of $0.06-0.18 \mathrm{mM}$ creatinine. Creatinine-induced oxidation suppression on $\mathrm{Ni}$ foam (Fig. 5a) was more evident: a $17 \%$ decrease with addition of $0.060 \mathrm{mM}$ creatinine, as opposed to $3 \%$ on NH F (Fig. 8a). Although peak current density differences are small in 

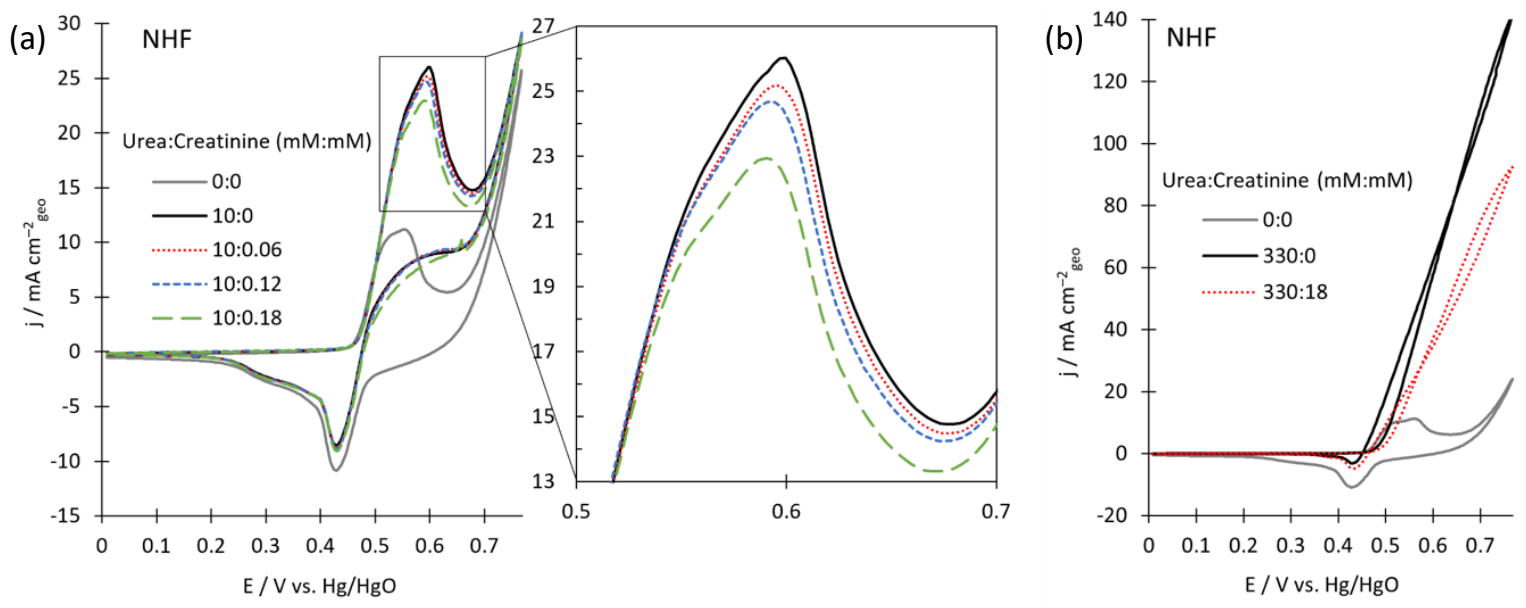

Fig. $8 \mathrm{CVs}$ of urea alone, and urea with creatinine in $1 \mathrm{M} \mathrm{KOH}$ on NHF for a) dialysaterelevant concentrations and b) urine-relevant concentrations

Fig. 8a, a trend emerges revealing that peak current density decreases with increasing creatinine concentration. This trend continues with the urine-relevant concentrations in Fig. 8b, showing a $43 \%$ charge decrease when $18 \mathrm{mM}$ creatinine was added to $330 \mathrm{mM}$ urea. The urine-relevant concentration experiments on NHF (Fig. 8b) demonstrate monotonically increasing behavior towards the urea oxidation reaction (UOR) without the oxidation peak seen on Ni foam (Fig. 3b). This associated higher reaction rate on NHF is due to the well-reported increased UOR activity of NHF compared to Ni catalyst [12]. Figures $5 \mathrm{a}, \mathrm{b}$ and $8 \mathrm{a}, \mathrm{b}$ demonstrate the existence of creatinine concentration-dependent UOR suppression on Ni foam and NHF, respectively.

\subsubsection{Fe-NHF}

Figures 9 and 10 show CVs of creatinine-only and urea/creatinine, respectively, on a Fe-NHF electrode. Like the other Ni-based electrodes, the presence of $0.18 \mathrm{mM}$ creatinine does not change the $\mathrm{Ni}^{2+} / \mathrm{Ni}^{3+}$ couple on the Fe-NHF electrode significantly. A creatinine concentration of $18 \mathrm{mM}$ increases the oxidation peak potential by $17 \mathrm{mV}$ and peak current density by $4 \mathrm{~mA} / \mathrm{cm}^{2}$ yielding a $7 \%$ increase in charge compared to the urea-only scan. In contrast to Figs. 4 and 8, Fig. 10a,b reveals enhanced oxidation current between 0.55 and $0.70 \mathrm{~V}$ on the positive scan when creatinine is added to urea on the Fe-NHF electrode. A $19-20 \%$ charge increase is seen for the dialysate-relevant addition of $0.06-0.18 \mathrm{mM}$ 


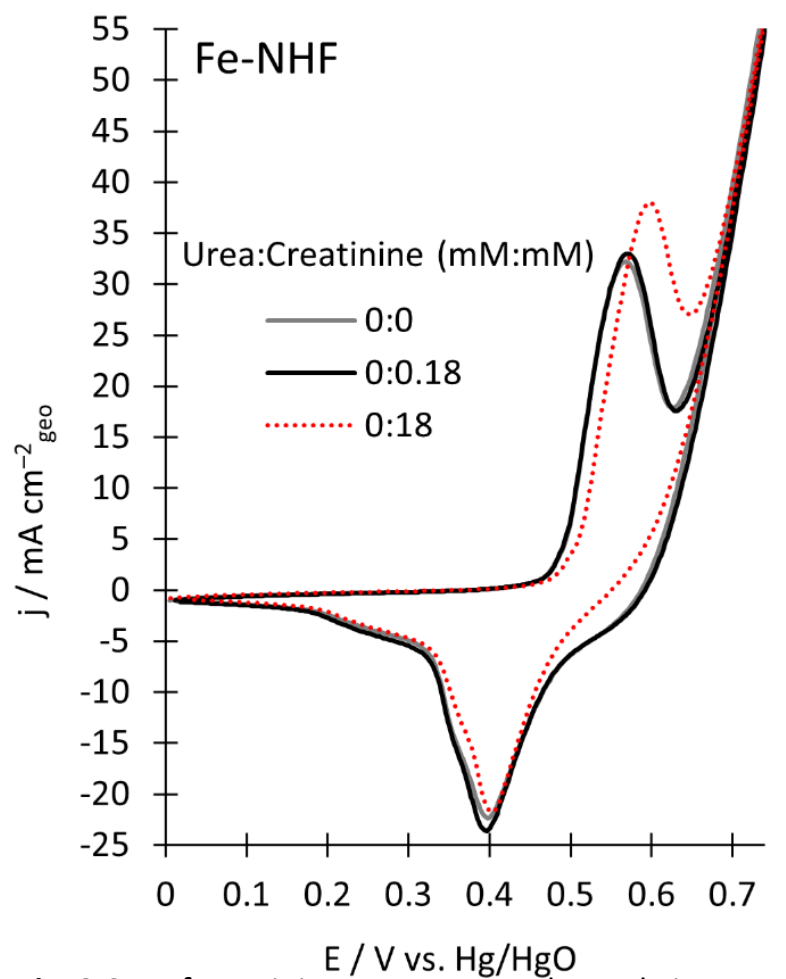

Fig. $9 \mathrm{CVs}$ of creatinine on a Fe-NHF electrode in $1 \mathrm{M} \mathrm{KOH}$

creatinine compared to $10 \mathrm{mM}$ urea alone on a Fe-NHF electrode (Fig. 10a). The associated OER region remains unaffected and the presence of creatinine, independent of concentration, enhances oxidation on the return scan as well (Fig. 10a). Similarly, the high concentration experiment (Fig. 10b) exhibits a 5\% increased oxidation charge when creatinine is added and indicates the possibility of co-oxidation of urea and creatinine, even in the OER region. The return scan for the creatinine-containing high concentration experiments (red dotted, Fig. 10b) crosses over itself, and the hysteresis causes it to fall below the return scan of the urea-only solution at voltages lower than $0.61 \mathrm{~V}$. Additionally, the $\mathrm{Ni}^{3+}$ reduction peak below $0.45 \mathrm{~V}$ for the dual solute scans (green dashed Fig. 10a and red dotted Fig. 10b) have more negative reduction current densities, which may indicate that fewer $\mathrm{Ni}^{2+}$ surface sites took place in the oxidation reactions of urea and creatinine [15], as discussed in section 4.

During a constant potential hold at $0.6 \mathrm{~V}$ for 15 minutes, the NHF electrode exhibits continuous urea oxidation, as shown in Fig. 11a. The presence of $0.18 \mathrm{mM}$ creatinine reduces the current density for the duration of the experiment resulting in a $19 \%$ decrease in oxidation charge over the 15 minutes, in 

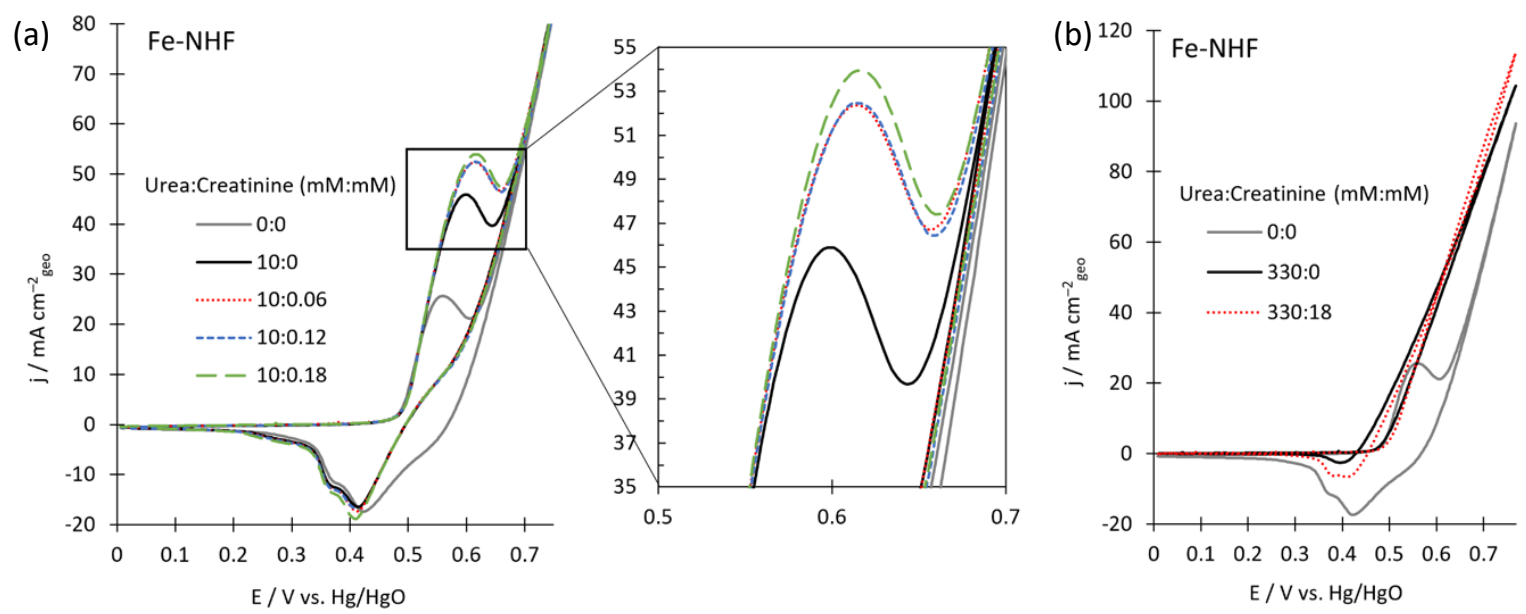

Fig. $10 \mathrm{CVs}$ of urea and creatinine in a) dialysate-relevant concentrations and b) urinerelevant concentrations on a Fe-NHF electrode in $1 \mathrm{M} \mathrm{KOH}$

agreement with the potentiodynamic results in Fig. 8a. The Fe-NHF electrode (Fig. 11b) shows increased OER (grey) and UOR (black) current density at $0.6 \mathrm{~V}$ compared to the associated NHF current (Fig. 11a), which can partly be attributed to an electrochemical surface area of Fe-NHF which is about twice that of NHF according to the blank CVs on each electrode. On Fe-NHF, the presence of 0.06 and $0.18 \mathrm{mM}$ creatinine suppressed oxidation charge by $15 \%$ and $8 \%$, in disagreement with the potentiodynamic charge enhancement seen in Fig. 10a. The first $60 \mathrm{~s}$ of each CA is nearly indistinguishable from each otheraside from current noise, which is noticeably lower at higher creatinine concentrations. Longer timescales differentiate the curves. Creatinine maximally suppresses the reaction at $0.06 \mathrm{mM}$ creatinine (Fig. $11 \mathrm{~b}$, red) with $0.18 \mathrm{mM}$ creatinine (Fig. 11b, blue) showing an overall charge enhancement compared to 0.06 $\mathrm{mM}$. Figure 11a,b confirms that a) creatinine does not limit overall oxidation as drastically on Fe-NHF as on NHF and that b) creatinine suppresses charge below that of UOR during a prolonged voltage hold on Fe-NHF, though evidence for co-electrooxidation is discussed in the next section.

\section{Discussion}

Typical concentrations of urea and creatinine in human urine are $220 \mathrm{mM}$ and $13 \mathrm{mM}$, respectively[6]; this study used $330 \mathrm{mM}$ urea and $18 \mathrm{mM}$ creatinine to better align with a 2018 study[7]. In dialysate, urea and creatinine exist in lower concentrations, about $10 \mathrm{mM}$ and $0.06 \mathrm{mM}$, respectively, as used in this 

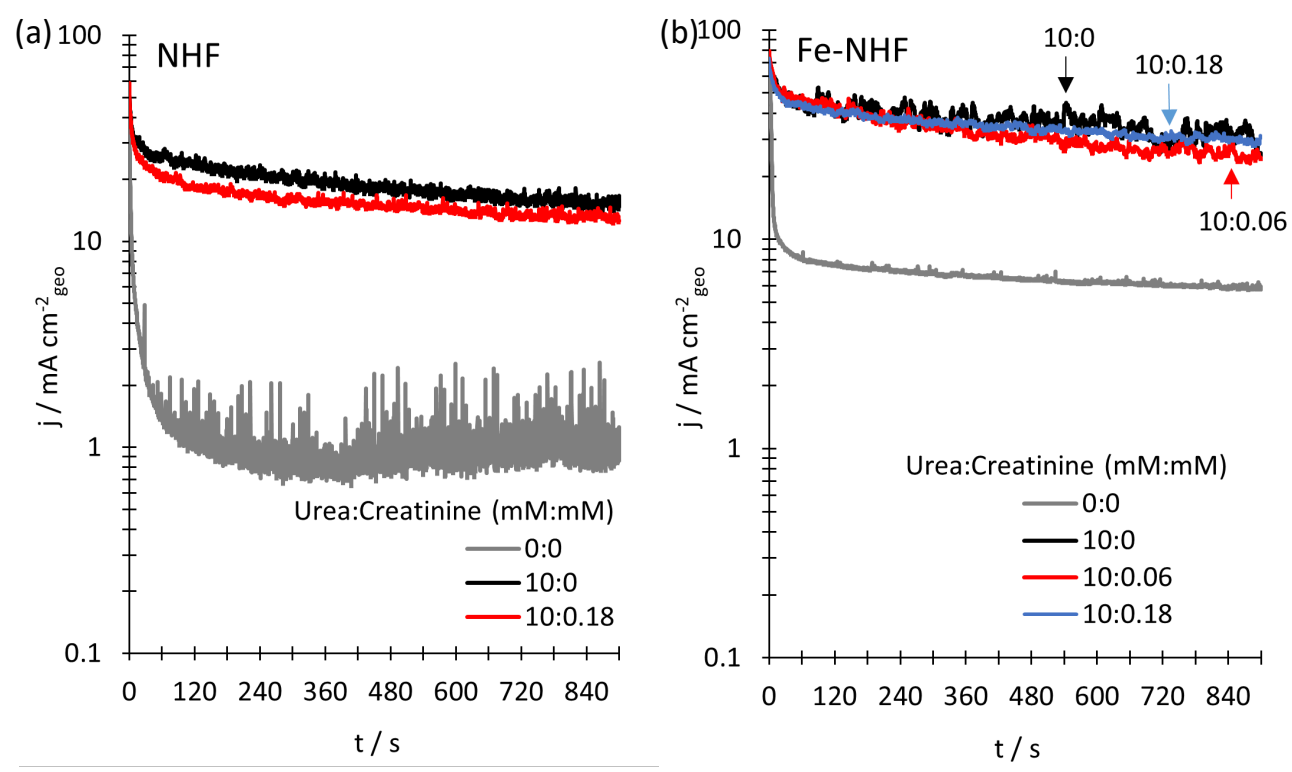

Fig. 11 Chronoamperometry of urea on a) NHF and b) Fe-NHF electrodes at 0.6 V with and without dialysate-relevant creatinine concentrations in $1 \mathrm{M} \mathrm{KOH}$

study. Additionally, 0.12 and $0.18 \mathrm{mM}$ creatinine were used in this study to understand concentrationdependent trends. Thus, the dialysate concentration regime in this study defines a solute ratio (urea: creatinine) which is 3-9 times higher than that of urine. The dialysate concentration regimes are a) more dilute, leading to lower oxidation currents, and b) have a lower proportion of creatinine molecules leading to less creatinine-induced oxidation effects. Table 3 summarizes the electrochemical results reported in section 3.2. Overall, the urine-relevant concentrations are more negatively (on Ni foam and NHF), and less positively (on Fe-NHF) affected by the addition of creatinine.

Spectroscopic investigation of creatinine and urea binding on $\mathrm{NiCo}_{2} \mathrm{O}_{4}$ in $\mathrm{pH} 14$ [7] indicates that creatinine forms a strong inner-sphere complex, while urea interacts weakly with the surface through

Table 3 Summary of changes in electrochemical oxidation charge $\left(Q_{o x}\right)$ with addition of creatinine on each electrode, within each concentration regime, and under different polarization conditions. "Dialysate-

\begin{tabular}{|c|c|c|c|c|}
\hline \multirow{2}{*}{ Electrode } & \multicolumn{2}{|c|}{ Experiment type } & \multicolumn{2}{c|}{ Creatinine effect on Q } \\
\cline { 2 - 5 } & potentiodynamic & potentiostatic & Dialysate-relevant & Urine-relevant \\
\hline Ni Foam & $\mathrm{x}$ & & $-17 \%$ & $-52 \%$ \\
\hline NHF & $\mathrm{x}$ & $\mathrm{x}$ & $-3 \%$ & $-43 \%$ \\
\hline Fe-NHF & & $\mathrm{x}$ & $-19 \%$ & - \\
\hline & & $\mathrm{x}$ & $+19 \%$ & $+5 \%$ \\
\hline
\end{tabular}


hydrogen bonds. As a result, when both solutes are present, the creatinine preferentially binds, limits urea access to the catalyst, and decreases overall current density. These results are in good agreement with our electrochemical results on $\mathrm{Ni}$ foam, and to a lesser extent on NHF, indicating that similar surface-specific molecular binding of creatinine may be limiting oxidation current. However, the introduction of $1 \mathrm{~mol} \%$ Fe to the NHF catalyst appears to have lessened the creatinine/surface interactions which allows the cooxidation of urea and creatinine.

The urease enzyme contains two $\mathrm{Ni}^{2+}$ atoms at the active site [22] which are required for the enzymatic degradation of urea via hydrolysis. Although it has been understood for decades that $\mathrm{Ni}^{2+}$ is essential to the activity of urease, its role in selectivity has yet to be fully realized [23]. It bears significance that nickel and Ni-containing electrodes often outperform noble metals and nanostructures materials $[1,24-26]$ as electrocatalysts for urea. Similarly, creatininase natively has two $\mathrm{Zn}^{2+}$ atoms in the active site, yet it has been found that enzyme activity increases when the metal centers are replaced by $\mathrm{Mn}^{2+}>\mathrm{Co}^{2+}>\mathrm{Mg}^{2+}>\mathrm{Fe}^{2+}>\mathrm{Ni}^{2+}=\mathrm{Zn}^{2+}[27]$. Like with urease, the metal cofactors in creatininase are known to be essential, but their role in catalyst selectivity is uncertain. Thus, it is hypothesized that surface interactions with the listed metal ions could improve binding of creatinine, even on electrocatalytic surfaces. The $\mathrm{NiCo}_{2} \mathrm{O}_{4}$ catalyst exhibited strong interactions with creatinine, which supports this hypothesis, and reaction rate increased at voltages above $0.65 \mathrm{~V}$ vs $\mathrm{Hg} / \mathrm{HgO}$ in $\mathrm{pH} 14$ [7]. The Fe-NHF electrode in this study behaved similarly at the same conditions (red dotted line in Fig. 10b). At lower potentials, the adsorbed creatinine molecules compete with-and contribute less oxidation current than - urea molecules to cause significant current suppression on $\mathrm{NiCo}_{2} \mathrm{O}_{4}$ and minor suppression on Fe-NHF at urine-relevant concentrations.

The increased current density during a potential sweep on Fe-NHF for creatinine-containing solutions (Fig. 10a,b) can be attributed to concurrent reactions of creatinine and urea. The two lower concentrations of creatinine $(0.06$ and $0.12 \mathrm{mM}$, red-dotted and blue-dashed lines of Fig. 10a) have overlapping CVs that show a significant increase in current density with respect to the urea-only CV. The 
higher concentration of $0.18 \mathrm{mM}$ creatinine (green-dashed line of Fig. 10a) yields a higher current density as expected.

In comparison with the chronoamperometry results of Fig. $11 \mathrm{~b}$, added creatinine results in a slightly lower current density at times beyond approximately 120 s relative to that of the urea-only case. This indicates the possibility of site blocking caused by stronger adsorption of creatinine, in line with the study by Schranck et al. [7] that reported strong creatinine blocking at urine-relevant concentrations. The site blocking indicated here is not complete, however, as continued reaction of creatinine is evident by virtue of the increased current density for the 10:0.18 solution (blue line) relative to that of the 10:06 solution (red line) at times beyond approximately $300 \mathrm{~s}$. Further evidence of incomplete site blocking is seen in current densities of urea/creatinine solutions more than four times that of the blank solution (gray line, Fig. 11b) at all times measured.

The differing time scales of measurement for the CV (Fig. 10a) and CA (Fig. 11b) results may explain the difference in creatinine-induced behavior observed in these two cases. Namely, the CV measurement occurred over a period of $10 \mathrm{~s}$, which is much less than that of the CA measurement of 120 s (the onset of creatinine-induced current decease) and beyond. This is explained by a slow build-up of site blocking that has little effect at $10 \mathrm{~s}$, but becomes noticeable at $120 \mathrm{~s}$.

\section{Conclusions}

The electrolysis of urea and creatinine on Ni-based electrodes was investigated electrochemically at both dialysate and urine-relevant concentrations. On a Ni foam electrode, the presence of creatinine severely limited urea oxidation reaction in both concentration regimes. A NHF electrode was more active towards urea oxidation, and oxidation charge was less suppressed by creatinine than for the Ni foam. A Fe-NHF electrode was most active toward both urea and creatinine oxidation, with the presence of creatinine enhancing charge during potentiodynamic experiments yet suppressing charge slightly during a 15-minute voltage hold for dialysate relevant concentrations. This behavior is attributed to concurrent urea and 
creatinine electrooxidation in the presence of site blocking by creatinine, which takes noticeable effect at times greater than $120 \mathrm{~s}$ at $0.6 \mathrm{~V} v s . \mathrm{Hg} / \mathrm{HgO}$.

\section{Acknowledgements}

This research was financially supported by Northwest Kidney Centers. Part of this work was conducted at the Molecular Analysis Facility, a National Nanotechnology Coordinated Infrastructure (NNCI) site at the University of Washington, which is supported in part by funds from the National Science Foundation (awards NNCI-2025489, NNCI-1542101), the Molecular Engineering \& Sciences Institute, and the Clean Energy Institute. This is a preprint of an article published in Journal of Applied Electrochemistry. The final authenticated version is available online at: https://doi.org/10.1007/s10800-021-01545-1.

\section{Conflicts of Interest/Competing Interests}

The authors report no conflict of interest or competing interests. 


\section{References}

1. Urbańczyk E, Sowa M, Simka W (2016) Urea removal from aqueous solutions - a review. J Appl Electrochem 46: . https://doi.org/10.1007/s10800-016-0993-6

2. Dbira S, Bensalah N, Ahmad MI, Bedoui A (2019) Electrochemical Oxidation/Disinfection of Urine Wastewaters with Different Anode Materials. Materials 12: . https://doi.org/10.3390/ma12081254

3. Boggs BK, King RL, Botte GG (2009) Urea electrolysis: direct hydrogen production from urine. Chem Commun 0:4859-4861 . https://doi.org/10.1039/B905974A

4. Keller RW, Yao SJ, Brown JM, Wolfson SK, Zeller MV (1980) Electrochemical removal of urea from physiological buffer as the basis for a regenerative dialysis system. J Electroanal Chem Interfacial Electrochem 116:469-485 . https://doi.org/10.1016/S0022-0728(80)80271-3

5. Wester M, Simonis F, Lachkar N, Wodzig WK, Meuwissen FJ, Kooman JP, Boer WH, Joles JA, Gerritsen KG (2014) Removal of urea in a wearable dialysis device: a reappraisal of electrooxidation. Artif Organs 38:998-1006 . https://doi.org/10.1111/aor.12309

6. Putnam DF (1971) Composition and concentrative properties of human urine

7. Schranck A, Marks R, Yates E, Doudrick K (2018) Effect of Urine Compounds on the Electrochemical Oxidation of Urea Using a Nickel Cobaltite Catalyst: An Electroanalytical and Spectroscopic Investigation. Environ Sci Technol 52:8638-8648 . https://doi.org/10.1021/acs.est.8b01743

8. Yao SJ, Wolfson SK, Krupper MA, Wu KJ (1984) Controlled-potential controlled-current electrolysis: In vitro and in vivo electrolysis of urea. Bioelectrochem Bioenerg 13:15-24 . https://doi.org/10.1016/0302-4598(84)85111-9

9. Lan R, Tao S, Irvine JTS (2010) A direct urea fuel cell - power from fertiliser and waste. Energy Environ Sci 3:438-441 . https://doi.org/10.1039/B924786F

10. King RL, Botte GG (2011) Investigation of multi-metal catalysts for stable hydrogen production via urea electrolysis. J Power Sources 196:9579-9584 . https://doi.org/10.1016/j.jpowsour.2011.06.079

11. Xu W, Wu Z, Tao S (2016) Urea-Based Fuel Cells and Electrocatalysts for Urea Oxidation. Energy Technol 4:1329-1337 . https://doi.org/10.1002/ente.201600185

12. Singh RK, Schechter A (2018) Electrochemical investigation of urea oxidation reaction on $\beta$ $\mathrm{Ni}(\mathrm{OH}) 2$ and $\mathrm{Ni} / \mathrm{Ni}(\mathrm{OH}) 2$. Electrochimica Acta 278:405-411 . https://doi.org/10.1016/j.electacta.2018.05.049

13. Vedharathinam V, Botte GG (2013) Direct evidence of the mechanism for the electro-oxidation of urea on $\mathrm{Ni}(\mathrm{OH}) 2$ catalyst in alkaline medium. Electrochimica Acta 108:660-665 . https://doi.org/10.1016/j.electacta.2013.06.137

14. Xie J, Liu W, Lei F, Zhang X, Qu H, Gao L, Hao P, Tang B, Xie Y (2018) Iron-Incorporated $\alpha$ $\mathrm{Ni}(\mathrm{OH}) 2$ Hierarchical Nanosheet Arrays for Electrocatalytic Urea Oxidation. Chem - Eur J 24:18408-18412 . https://doi.org/10.1002/chem.201803718 
15. Vedharathinam V, Botte GG (2012) Understanding the electro-catalytic oxidation mechanism of urea on nickel electrodes in alkaline medium. Electrochimica Acta 81:292-300 .

https://doi.org/10.1016/j.electacta.2012.07.007

16. Zhan S, Zhou Z, Liu M, Jiao Y, Wang H (2019) 3D NiO nanowalls grown on Ni foam for highly efficient electro-oxidation of urea. Catal Today 327:398-404 .

https://doi.org/10.1016/j.cattod.2018.02.049

17. Ren J-T, Yuan G-G, Weng C-C, Chen L, Yuan Z-Y (2018) Uniquely integrated Fe-doped Ni(OH)2 nanosheets for highly efficient oxygen and hydrogen evolution reactions. Nanoscale 10:10620 10628 . https://doi.org/10.1039/C8NR01655K

18. Wang G, Ye K, Shao J, Zhang Y, Zhu K, Cheng K, Yan J, Wang G, Cao D (2018) Porous Ni2P nanoflower supported on nickel foam as an efficient three-dimensional electrode for urea electrooxidation in alkaline medium. Int J Hydrog Energy 43:9316-9325 .

https://doi.org/10.1016/j.ijhydene.2018.03.221

19. Ye K, Wang G, Cao D, Wang G (2018) Recent Advances in the Electro-Oxidation of Urea for Direct Urea Fuel Cell and Urea Electrolysis. Top Curr Chem 376:42 .

https://doi.org/10.1007/s41061-018-0219-y

20. Hall DS, Lockwood DJ, Bock C, MacDougall BR (2015) Nickel hydroxides and related materials: a review of their structures, synthesis and properties. Proc Math Phys Eng Sci R Soc 471: . https://doi.org/10.1098/rspa.2014.0792

21. Liu D, Liu T, Zhang L, Qu F, Du G, Asiri AM, Sun X (2017) High-performance urea electrolysis towards less energy-intensive electrochemical hydrogen production using a bifunctional catalyst electrode. J Mater Chem A 5:3208-3213 . https://doi.org/10.1039/C6TA11127K

22. Nim YS, Wong K-B (2019) The Maturation Pathway of Nickel Urease. Inorganics 7:85 . https://doi.org/10.3390/inorganics7070085

23. Zambelli B, Musiani F, Benini S, Ciurli S (2011) Chemistry of Ni2+ in Urease: Sensing, Trafficking, and Catalysis. Acc Chem Res 44:520-530 . https://doi.org/10.1021/ar200041k

24. Simka W, Piotrowski J, Nawrat G (2007) Influence of anode material on electrochemical decomposition of urea. Electrochimica Acta 52:5696-5703 . https://doi.org/10.1016/j.electacta.2006.12.017

25. Li H, Yu Q, Yang B, Li Z, Lei L (2015) Electro-catalytic oxidation of artificial human urine by using BDD and IrO2 electrodes. J Electroanal Chem 738:14-19 . https://doi.org/10.1016/j.jelechem.2014.11.018

26. Wright JC, Michaels AS, Appleby AJ (1986) Electrooxidation of urea at the ruthenium titanium oxide electrode. AIChE J 32:1450-1458 . https://doi.org/10.1002/aic.690320906

27. Rikitake K, Oka I, Ando M, Yoshimoto T, Tsuru D (1979) Creatinine Amidohydrolase (Creatininase) from Pseudomonas putida: ePurification and Some Properties. J Biochem (Tokyo) 86:1109-1117 . https://doi.org/10.1093/oxfordjournals.jbchem.a132605 